\title{
Infliximab improves vascular stiffness in patients with rheumatoid arthritis
}

\author{
M Wong, ${ }_{1}^{1}$ S P Oakley, ${ }^{2}$ L Young, ${ }^{3}$ B Y Jiang, ${ }^{4}$ A Wierzbicki, ${ }^{4}$ G Panayi, ${ }^{5}$ P Chowienczyk, \\ B Kirkham ${ }^{3}$
}

${ }^{1}$ Guy's and St Thomas' Hospital, London, UK and St Vincent's Hospital, Melbourne, Australia; ${ }^{2}$ Guy's and St Thomas' Hospital and King's College, London, UK and Rheumatology, Royal Newcastle Centre, Newcastle, Australia; ${ }^{3}$ Guy's and St Thomas' Hospital, London, UK;

${ }^{4}$ St Thomas' Hospital and King's College, London, UK; ${ }^{5}$ King's College, London, UK

Correspondence to:

Dr B Kirkham, Department of Rheumatology, Guy's Hospital, London SE1 9RT, UK: brucekrheum@hotmail.com

MW and SPO contributed equally to this work and appear as equal first authors.

Accepted 22 August 2008

Published Online First

16 October 2008

\section{ABSTRACT}

Objectives: Patients with rheumatoid arthritis (RA) have increased cardiovascular mortality. Tumour necrosis factor $\alpha$ (TNF $\alpha$ )-blocking therapy has been shown to reduce RA disease activity measures and joint damage progression. Some observational studies suggest that TNF $\alpha$ blockade reduces mortality and incidence of first cardiovascular events. The mechanisms contributing to these outcomes are unclear. This study assessed the effects of infliximab treatment on vascular stiffness and structure in patients with RA.

Methods: A post hoc analysis of longitudinal data from a randomised placebo controlled study evaluated the effect of infliximab on vascular assessments. 26 patients received intravenous infliximab $(3 \mathrm{mg} / \mathrm{kg}$ ) at weeks $0,2,6$ and every 8 weeks thereafter to week 54 . Patients were followed up to 56 weeks of infliximab therapy with assessments of RA disease activity, cardiovascular risk factors, vascular stiffness (pulse wave velocity (PWV)), carotid intima media thickness (CIMT) and carotid artery plaque (CAP). Univariate analyses of changes over time by repeated measures analysis of variance (ANOVA) were followed by multivariate time-series regression analysis (TSRA) if changes were seen.

Results: PWV was significantly lower (better) after 56 weeks of treatment with infliximab (ANOVA $p<0.01$, TSRA $p<0.01$ ). However, CIMT (ANOVA $p=0.50$ ) and CAP $\left(\chi^{2}=4.13, p=0.88\right)$ did not change over the study period. Multiple cardiovascular risk measures did not change with treatment and did not correlate with changes in measures of vascular structure.

Conclusions: Arterial stiffness improves with infliximab treatment in RA. This change may help explain the improved cardiovascular disease survival in patients with $\mathrm{RA}$ receiving TNF $\alpha$-blocking therapy.

Rheumatoid arthritis (RA) is associated with increased cardiovascular morbidity and mortality. ${ }^{1}$ Patients with RA have a higher risk of cardiovascular events ${ }^{2}{ }^{3}$ not explained entirely by traditional cardiovascular risk factors, ${ }^{4}$ implying that cardiovascular disease is an extra-articular manifestation of RA. ${ }^{5}$

Tumour necrosis factor $\alpha(\mathrm{TNF} \alpha)$ is a proinflammatory cytokine central to the pathology of RA and may also promote vascular disease. ${ }^{67}$ TNF $\alpha$-blocking drugs reduce inflammation and joint damage in $\mathrm{RA}^{8-11}$ and may reduce mortality ${ }^{12}$ and cardiovascular disease. ${ }^{13}{ }^{14}$ Data indicate that patients responding to $\mathrm{TNF} \boldsymbol{\alpha}$-blocking therapy within the first 6 months have a greater reduction in the incidence of myocardial infarction compared with non-responders. ${ }^{15}$ Surrogate vascular measures have been used to indicate early atherosclerosis and predict increased future cardiovascular risk Increased arterial stiffness, increased carotid intima media thickness (CIMT) and endothelial dysfunction have been demonstrated in patients at increased risk of and with known cardiovascular disease. ${ }^{16} 17$ They have also been found to be independent predictors of future cardiovascular events. ${ }^{18} 19$ Carotid-femoral pulse wave velocity (PWV) is now used as a therapeutic end point in studies of antihypertensive treatments. ${ }^{20}$ All of these measures have been reported to be abnormal in patients with RA. ${ }^{21-23}$ Improvement in arterial stiffness has been reported in RA after TNF $\alpha$-blocking therapy with etanercept. ${ }^{24}$ Previous reports of CIMT in response to TNF $\alpha$ blockade indicate mixed results. ${ }^{21}{ }^{25}$

There is conflicting evidence regarding the roles of conventional cardiovascular risk factors in the pathogenesis of atherosclerosis in RA. Oxidised low-density lipoprotein (LDL) is thought to be particularly atherosclerogenic. ${ }^{26}$ Adiponectin is an adipokine associated with the metabolic syndrome and possibly with accelerated atherosclerosis. ${ }^{27}$ The relationship of these two factors with atherosclerosis in the setting of RA has not been evaluated.

This longitudinal study examined the effects of infliximab on vascular stiffness and structure in patients with RA and measured changes in multiple risk factors for atherosclerotic disease including oxidised LDL and adiponectin. We evaluated this initially as a randomised controlled trial and then undertook a post hoc re-evaluation when the entire cohort received infliximab.

\section{METHODS}

\section{Patients}

Adult subjects ( $\geqslant 18$ years) with RA defined by American College of Rheumatology criteria $^{28}$ referred for TNF $\alpha$-blocking therapy according to the British Society of Rheumatology (BSR) criteria were recruited from outpatient clinics at Guy's and St Thomas' Hospitals between January 2004 and June 2005. Patients were invited to participate if they had failed on two disease-modifying antirheumatic drugs including methotrexate, and had a disease activity score 28 (DAS28) $>5.1$ on two occasions at least 4 weeks apart. All patients were taking methotrexate ( $\leqslant 25 \mathrm{mg} /$ week). All antirheumatic medications remained stable for at least 4 weeks preceding and during the study unless changes in dose were medically indicated.

Exclusion criteria were chosen in an effort to exclude patients with traditional cardiovascular risk factors or drug treatments that may confound results. Patients were therefore excluded from the 
study if they had a history of ischaemic heart disease, cerebrovascular disease, peripheral vascular disease, diabetes mellitus, treatment with aspirin or prednisolone at a dose $>10 \mathrm{mg} /$ day and previous treatment with infliximab or any therapeutic agent targeted at TNF $\alpha$. Patients with evidence of current or previous infection with tuberculosis, regardless of previous treatment, were excluded.

\section{Protocol}

In a randomised, placebo controlled, double-blind study, patients were allocated using a 2:1 randomisation procedure to infliximab or placebo. Infliximab $3 \mathrm{mg} / \mathrm{kg}$ was administered by intravenous infusion at weeks $0,2,6$ and every 8 weeks thereafter for a total of 54 weeks. Patients randomised to placebo received saline infusions for the first 22 weeks and switched to open-label infliximab at week 24. Patients in the placebo group with worsening RA disease activity at week 14 were permitted to escape to open-label infliximab at week 16. The primary outcome measures were vascular ultrasound assessments at weeks 24 and 56 ( 2 weeks after infusions to assess maximal improvement). Secondary outcome measures included RA disease activity and cardiovascular risk factors.

\section{Assessment of RA disease activity}

RA disease activity was assessed at baseline, 8, 16, 24, 40 and 56 weeks by the modified Health Assessment Questionnaire (HAQ), ${ }^{29} 28$ swollen and tender joint counts, erythrocyte sedimentation rate (ESR), patient global assessment using a $100 \mathrm{~mm}$ visual analogue scale and DAS28. ${ }^{30}$

\section{Assessment of cardiovascular risk factors}

Cardiovascular risk factors included systolic and diastolic blood pressure (BP), C-reactive protein (CRP), serum fasting lipid profile (total cholesterol, high- and low-density lipoprotein fractions (HDL, LDL) and triglycerides), oxidised LDL, insulin resistance measured by log homeostasis model assessment $(\mathrm{HOMA})^{31}$ and adiponectin. ${ }^{27}$ Subjects who had smoked within the last 2 years were categorised as current smokers. BP, heart rate and HsCRP were assessed at baseline, 8, 16, 24, 40 and 56 weeks. Lipid profiles and HOMA were measured at 0, 24, 40 and 56 weeks and adiponectin at 0,24, 40 and 56 weeks.

\section{Vascular assessments}

BP and assessment of vascular stiffness (PWV), structure (CIMT), augmentation index (AI) and carotid artery (atherosclerotic) plaque (CAP) were measured in supine fasting subjects in a quiet room with temperature controlled to $22^{\circ} \mathrm{C}$. Antihypertensive, anti-inflammatory and cyclo-oxygenase- 2 inhibitor medications were withheld $24 \mathrm{~h}$ before assessment. $\mathrm{BP}$ was measured using an Omron BP monitor. The mean of three measurements was recorded for each vascular assessment. The ultrasonographer was blind to the treatment status of the patients during the randomised controlled phase of the study.

\section{Arterial stiffness: pulse wave velocity (PWV)}

Carotid-femoral PWV was measured at baseline and after 24 and 56 weeks of treatment as the time delay between the rapid upstroke of the carotid and femoral artery pulse waves using the PWA system (SphygmoCor, PWA Medical, Sydney, Australia). The distance between the two arterial points was measured on the surface of the body using a tape measure. PWV was calculated as the distance travelled by the arterial pulse wave in metres divided by the time delay between the two arterial points in seconds (intra-observer reliability ICC $=0.84, \mathrm{~N}=12$ subjects with RA).

\section{Arterial structure: carotid intima media thickness (CIMT)}

CIMT was measured at weeks 0 and 56 using ECG-triggered high-resolution duplex ultrasonography (Acuson XP10) with a 7.5 $\mathrm{MHz}$ vascular probe. Measurements were performed on the common carotid arteries $1-2 \mathrm{~cm}$ proximal to the bulb and studied in longitudinal and transverse planes with anterior, lateral and posterior approaches. The average of the measurements of the anterior, lateral and posterior projections of the far wall performed on each side was used to calculate the CIMT for each subject (intra-observer reliability ICC $=0.98, \quad N=12$ subjects with RA).

\section{Augmentation index (Al)}

AI is a method of pulse wave analysis (PWA) performed using applanation tonometry of the radial artery (PWA system, SphygmoCor); it was measured at weeks 0,24 and 56. The PWA system acquires 10-12 sequential waveforms and generates an averaged radial and mathematically-derived corresponding central aortic waveform. AI is derived from the estimated aortic waveform and is defined as the increase in pressure from the first systolic peak/shoulder to the second systolic peak/shoulder expressed as a percentage of pulse pressure (intra-observer reliability ICC $=0.86, \mathrm{~N}=8$ subjects with RA).

\section{Carotid artery plaque (CAP)}

CAP was measured by ultrasound at weeks 0, 24 and 56. A grade of 0 was assigned for no plaque, 1 for minimal plaque and 2 for extensive plaque. A combined score for the right and left carotid arteries was calculated as the sum of the right and the left scores for each individual subject on a scale of $0-4$.

\section{Statistical analysis}

\section{Sample size calculation}

The sample size was estimated for a 2:1 (infliximab: placebo) randomised controlled trial using unpublished paired assessments of PWV in 12 patients with RA (mean 8.88, $\sigma 2.12 \mathrm{~m} / \mathrm{s}$ (first assessment) and reliability ICC 0.84. Smallest detectable difference $(\Delta)$ was calculated as $3.23,{ }^{32}$ giving a required sample size of six patients per group $(\alpha=0.05$, power $=0.80)$. Assuming a $30 \%$ drop-out rate, we aimed to recruit 9 patients for placebo and 18 for treatment.

\section{Intention-to-treat analysis}

Assessments of RA disease activity, BP and heart rate were compared between subjects in the treatment and placebo arms by a two-sided Student $t$ test at 0,8 and 16 weeks. Follow-up vascular assessments were not performed within the 16-week placebo controlled phase and, as such, could not be included in the analysis.

\section{Post hoc analyses}

Post hoc multivariate ANOVA modelling was performed to evaluate the effects of treatment with infliximab (vs placebo) and duration of treatment ( 0 vs 8 vs 16 weeks) on disease activity, systolic and diastolic blood pressure and heart rate during the initial controlled part of the trial.

Because all subjects in the placebo arm elected to "escape" to the treatment arm at 16 weeks, a second post hoc analysis was performed to evaluate trends in all subjects over time during 
Table 1 Baseline patient characteristics

\begin{tabular}{|c|c|c|c|c|c|c|c|}
\hline & \multirow{2}{*}{$\begin{array}{l}\text { Infliximab } \\
(\mathrm{n}=17)\end{array}$} & \multirow{2}{*}{$\begin{array}{l}\text { Placebo } \\
(\mathrm{n}=9)\end{array}$} & \multirow[b]{2}{*}{ Test } & \multirow[b]{2}{*}{ p Value } & \multicolumn{3}{|l|}{ Total } \\
\hline & & & & & Mean & SD & Range \\
\hline \multicolumn{8}{|l|}{ Demographics } \\
\hline Gender (proportion female) & $14 / 17$ & $8 / 9$ & $\chi^{2}$ test & 0.660 & $22 / 26$ & & \\
\hline Age (years) & $48(12)$ & $50(16)$ & $t$ test & 0.663 & 49 & (14) & $29-77$ \\
\hline \multicolumn{8}{|l|}{ Vascular assessments } \\
\hline PWV (m/s) & $8.8(1.4)$ & $9.4(2.3)$ & $t$ test & 0.438 & 9.0 & $(1.7)$ & $6.5-12.7$ \\
\hline Mean CIMT (mm) & $0.9(0.3)$ & $0.9(0.3)$ & $t$ test & 0.709 & 0.9 & $(0.3)$ & $0.4-1.6$ \\
\hline $\begin{array}{l}\text { CAP (number with each } \\
\text { combined grade } 0 / 1 / 2 / 3 / 4 \text { ) }\end{array}$ & $9 / 4 / 2 / 1 / 1$ & $7 / 0 / 0 / 2 / 0$ & $\chi^{2}$ test & 0.226 & $16 / 4 / 2 / 3 / 1$ & & \\
\hline \multicolumn{8}{|l|}{ RA disease activity } \\
\hline RF-positive (proportion) & $7 / 16$ & $7 / 8$ & $\chi^{2}$ test & 0.040 & $14 / 24$ & & \\
\hline ESR $(\mathrm{mm} / \mathrm{h})$ & $39(26)$ & $40(24)$ & $t$ test & 0.882 & 39 & (24) & $3-88$ \\
\hline $\mathrm{CRP}(\mathrm{mg} / \mathrm{l})$ & $32(47)$ & $30(21)$ & $t$ test & 0.898 & 32 & (39) & $4-186$ \\
\hline $\begin{array}{l}\text { Patient global assessment } \\
(100 \mathrm{~mm})\end{array}$ & $68(15)$ & $70(25)$ & $t$ test & 0.829 & 69 & (18) & $37-100$ \\
\hline $\begin{array}{l}\text { Tender joint count } \\
\text { (out of 28) }\end{array}$ & $14(7)$ & $15(7)$ & $t$ test & 0.837 & 14.5 & $(6.8)$ & $3-26$ \\
\hline $\begin{array}{l}\text { Swollen joint count } \\
\text { (out of 28) }\end{array}$ & $10(5)$ & $12(5)$ & $t$ test & 0.286 & 10.5 & (5.1) & $3-21$ \\
\hline DAS28 & $6.2(0.9)$ & $6.4(0.8)$ & $t$ test & 0.554 & 6.3 & $(0.8)$ & $5.2-7.9$ \\
\hline \multicolumn{8}{|l|}{ Cardiovascular risks } \\
\hline $\begin{array}{l}\text { Smoking status (non/ex/ } \\
\text { current), N }\end{array}$ & $9 / 5 / 3$ & $5 / 3 / 1$ & $\chi^{2}$ test & 0.905 & $14 / 8 / 4$ & & \\
\hline Heart rate (beats/min) & $69(11)$ & $72(11)$ & $t$ test & 0.570 & 70 & (11) & $47-90$ \\
\hline Systolic BP (mm Hg) & $121(14)$ & $124(18)$ & $t$ test & 0.642 & 122 & (15) & $97-153$ \\
\hline Diastolic BP (mm Hg) & $75(7)$ & $74(8)$ & $t$ test & 0.951 & 74 & (8) & $66-99$ \\
\hline $\mathrm{BMI}\left(\mathrm{kg} / \mathrm{m}^{2}\right)$ & $26.0(6.7)$ & $25.7(6.7)$ & $t$ test & 0.921 & 25.8 & (7) & $17-42$ \\
\hline Total cholesterol $(\mathrm{mmol} / \mathrm{l})$ & $5.1(1.2)$ & $4.7(0.8)$ & $t$ test & 0.242 & 4.9 & $(1.1)$ & $2.9-7.6$ \\
\hline LDL cholesterol (mmol/l) & $3.3(1.0)$ & $2.9(0.7)$ & $t$ test & 0.369 & & & \\
\hline HDL cholesterol (mmo//l) & $1.3(0.4)$ & $1.2(0.3)$ & $t$ test & 0.568 & 1.3 & $(0.4)$ & $0.8-2.3$ \\
\hline Triglycerides (mmol/l) & $1.0(0.5)$ & $0.8(0.3)$ & $t$ test & 0.207 & 3.2 & $(0.9)$ & $1.3-5.1$ \\
\hline HOMA & $12.4(10.1)$ & $6.8(3.1)$ & $t$ test & 0.214 & 10.7 & (8.9) & $3.1-34.9$ \\
\hline Adiponectin & $18773(7168)$ & $18523(6898)$ & $t$ test & 0.933 & 18686 & (6938) & $7075-36623$ \\
\hline
\end{tabular}

Data reported as mean (SD) unless otherwise noted.

$\mathrm{BMI}$, body mass index; $\mathrm{BP}$, blood pressure; CAP, carotid artery plaque; CIMT, carotid intimal medial thickness; CRP, C-reactive protein; DAS, disease activity score; ESR, erythrocyte sedimentation rate; HDL, high-density lipoprotein; HOMA, insulin resistance measured by log homeostasis model assessment; LDL, low-density lipoprotein; PWV, pulse wave velocity; RA, rheumatoid arthritis; RF, rheumatoid factor.

treatment with infliximab. For patients in the placebo arm, the baseline infliximab assessment was at the end of the placebo controlled phase at 16 weeks, the 8-week assessment was at week 24, the week 24 assessment was at week 40, and the week 40 assessment was at week 56. Preliminary univariate analysis was performed to identify possible changes during infliximab. For continuous data the changes over time from pretreatment to 24 and 56 weeks were evaluated by repeated measures analysis of variance (RM ANOVA) with time point comparisons using Bonferroni-corrected $t$ tests. Assessments of CAP, being categorical data, were evaluated by the $\chi^{2}$ test. Vascular assessments that changed during infliximab therapy were further explored for possible confounding influences by simple correlation followed by time-series regression analysis with linear random intercepts models accounting for clustering within individuals. In this analysis we used all available observations preceding and during infliximab treatment. Potentially modifiable cardiovascular risk factors that correlated with the vascular assessment at baseline with $r>0.20$ were evaluated.

The study database was generated by the Trial Coordination Center (TCC), Groningen, The Netherlands. All entries were double-entered to ensure complete and accurate data capture, and all data queries answered before the database was cleaned and locked. Statistical analysis was performed using Stata Version 6.0 (Statacorp, Texas, USA).

\section{RESULTS}

Twenty-six subjects were enrolled in the study; 17 were randomised to infliximab and 9 to placebo. All 9 subjects in the placebo arm elected to take the escape arm after 14 weeks. A greater proportion of patients in the treatment arm were rheumatoid factor positive, otherwise baseline characteristics were similar across the groups (table 1).

\section{Intention-to-treat analysis}

The results for the placebo controlled double-blind phase of the study are shown in fig 1 . Tender and swollen joint counts, patient global assessments and DAS28 scores were all significantly lower in the treatment arm by 8 and 16 weeks. ESR was significantly better in the treatment arm at 8 weeks but not at 16 weeks. Heart rate, CRP, systolic and diastolic BP were not significantly different at 8 or 16 weeks. Arterial stiffness, lipid profiles, HOMA and adiponectin were not assessed during the placebo controlled phase of the study.

\section{Post hoc analysis}

Post hoc multivariate ANOVA modelling of the initial controlled phase of the trial confirmed the effect of treatment on disease activity (DAS28, ESR, tender and swollen joint counts) but not heart rate, systolic and diastolic BP. In the 

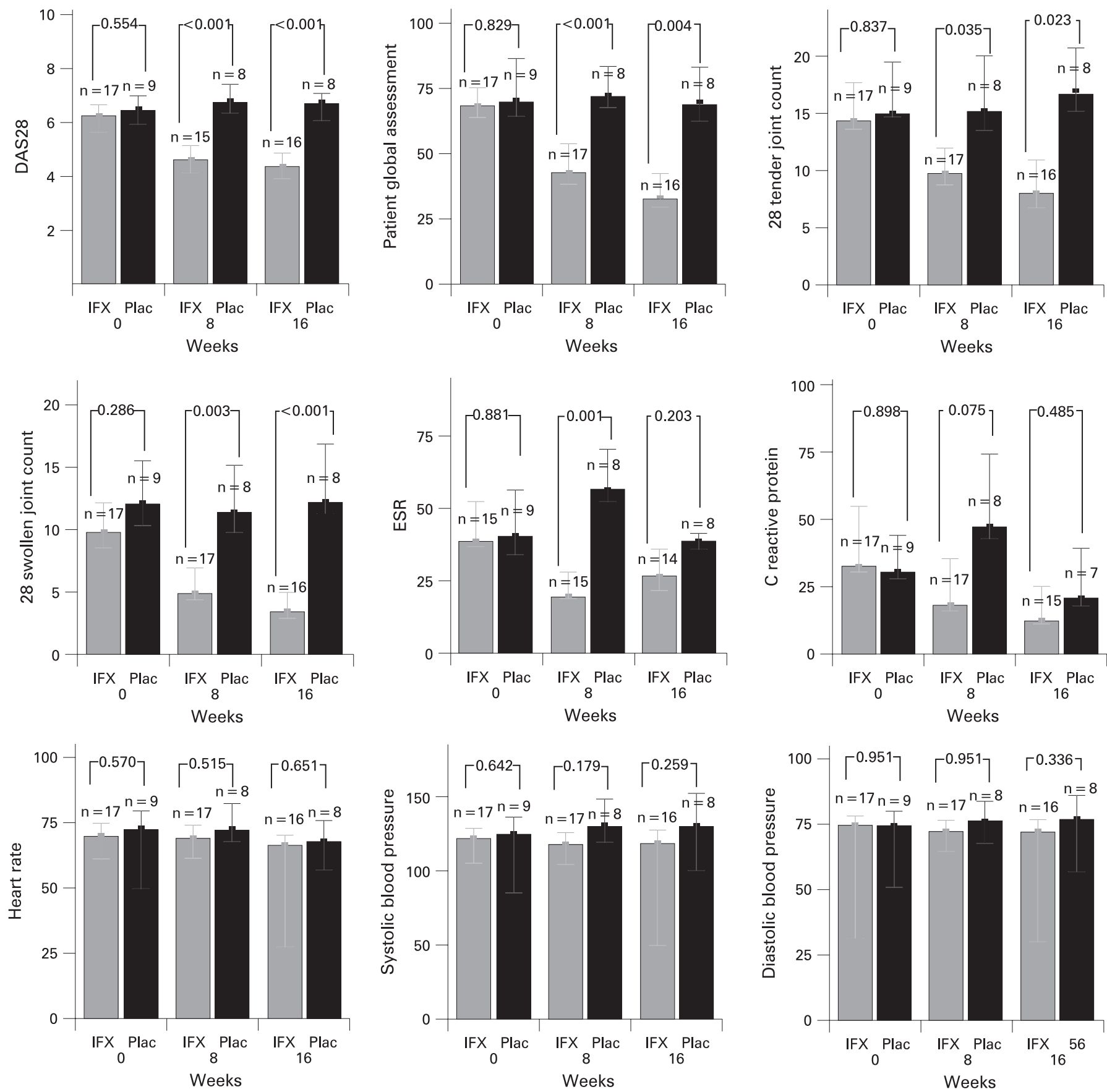

Infliximab Bars show means
$\begin{aligned} & \text { Placebo } \quad \text { Error bars show }+/-2 \text { standard error of the mean } \\ & \text { treatment and placebo arms have been compared by 2-tailed t test }\end{aligned}$

Figure 1 Comparison of disease activity (DAS), heart rate, systolic and diastolic blood pressure in infliximab (IFX) and placebo (Plac) groups during the placebo controlled phase of the trial. ESR, erythrocyte sedimentation rate.

second post hoc analysis, evaluating trends in all patients as they received infliximab, RM ANOVA showed a significant reduction in arterial stiffness (PWV, $\mathrm{p}=0.004$ ) over 56 weeks (fig 2). However, CIMT $(p=0.499)$, AI $(p=0.265)$ and CAP $\left(\chi^{2}=4.13, p=0.88\right.$; data not shown) did not change. RA disease activity (DAS28, tender and swollen joint counts, patient global scores and ESR) improved significantly $(p<0.05$, fig 2$)$. There were no significant changes in systolic BP $(p=0.506)$ or diastolic BP $(p=0.835)$, triglycerides $(p=0.830)$ or adiponectin levels $(p=0.962)$, although HOMA $(p=0.540)$ showed a nonsignificant decrease and serum HDL $(p=0.336)$ showed nonsignificant increases (fig 3).

Influences on PWV were explored further by univariate Pearson correlation (data not shown). PWV correlated most strongly with age at enrolment $(r=0.64, \mathrm{~N}=26, \mathrm{p}<0.01)$ and, to a lesser extent, with heart rate $(r=0.39, N=70, p<0.01)$, systolic $\mathrm{BP}(\mathrm{r}=0.45, \mathrm{~N}=70, \mathrm{p}<0.01)$, serum $\mathrm{HDL}(\mathrm{r}=-0.35$, $\mathrm{N}=70, \mathrm{p}<0.01)$, serum triglycerides $(\mathrm{r}=0.25, \mathrm{~N}=63, \mathrm{p}<0.05)$ 

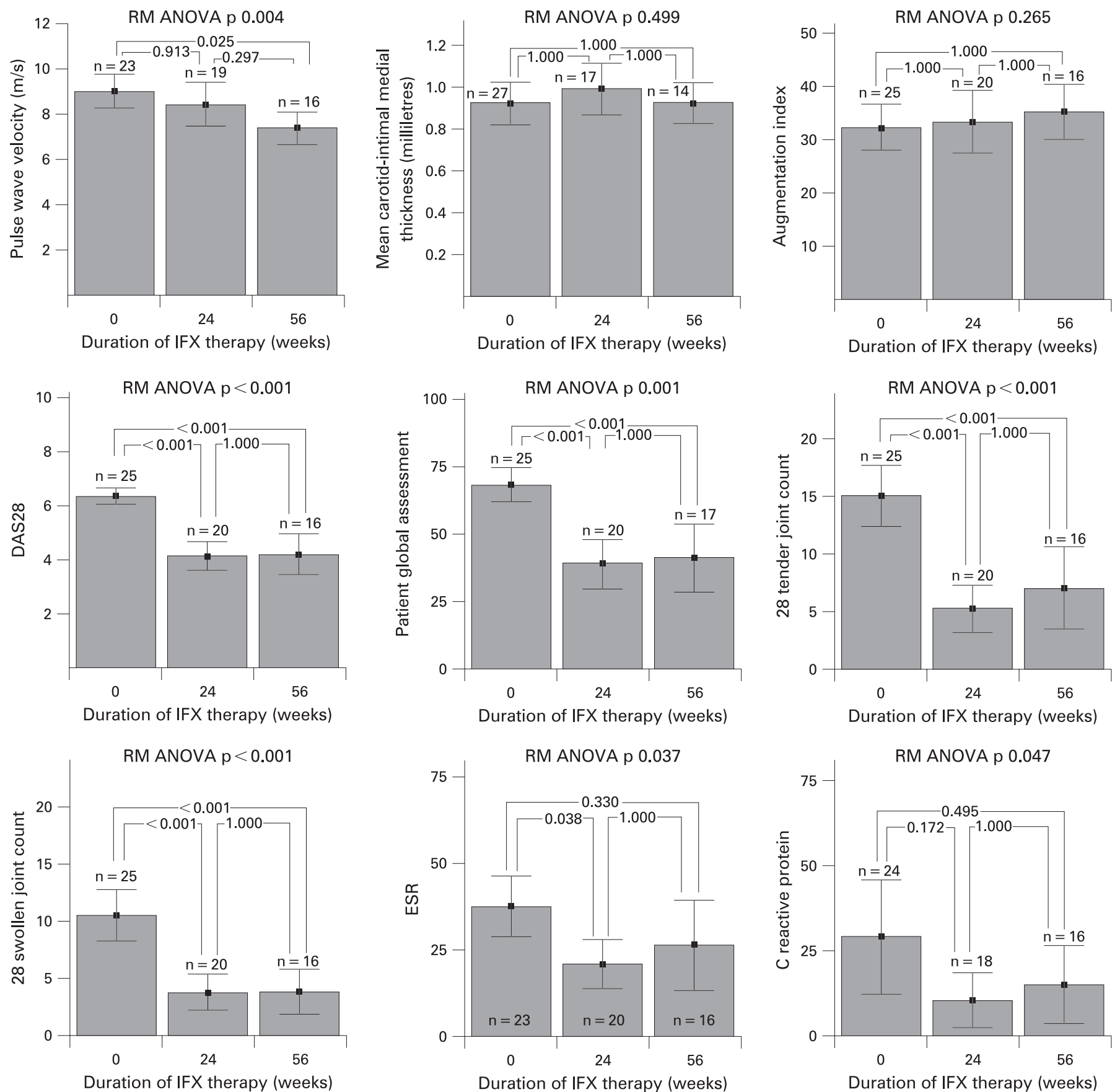

Figure 2 Post hoc analysis: trends in vascular measurements and rheumatoid arthritis disease activity (DAS) during treatment with infliximab (IFX). Repeated measures (RM) ANOVA p values indicate the significance of the overall trend while comparison between paired time points are compared by $t$ tests adjusted for multiple comparisons (Bonferroni correction). ESR, erythrocyte sedimentation rate.

and total serum cholesterol $(r=-0.17, \mathrm{~N}=63, \mathrm{p}=0.19)$. PWV also correlated negatively with duration of infliximab treatment $(\mathrm{r}=-0.34, \mathrm{~N}=70, \mathrm{p}<0.01)$ and positively with patient global assessment $(r=0.26, N=70, p=0.03)$ and DAS28 $(r=0.23$, $\mathrm{N}=70, \mathrm{p}=0.06$ ). Multivariate time-series regression modelling found that duration of infliximab treatment (negative correlation) and heart rate (positive correlation) were the only significant influences on PWV (table 2).

\section{DISCUSSION}

This study evaluated the effect of TNF $\alpha$-blocking therapy on vascular structure in RA. The placebo controlled part of the study was unable to assess vascular effects of infliximab due to early drop-out of the placebo group. The post hoc analysis of long-term treatment showed that arterial stiffness (PWV) improved after treatment with infliximab for 56 weeks. CIMT, AI and CAP did not change over the course of the study. Although we showed significant improvements in vascular stiffness, the mechanisms of this improvement remain unclear. We measured multiple modifiable cardiovascular risk factors but these did not change significantly during infliximab treatment. This may reflect a type II error owing to the small study size. However, the fact that significant changes were seen in PWV and not in any other cardiovascular risk factor suggests 


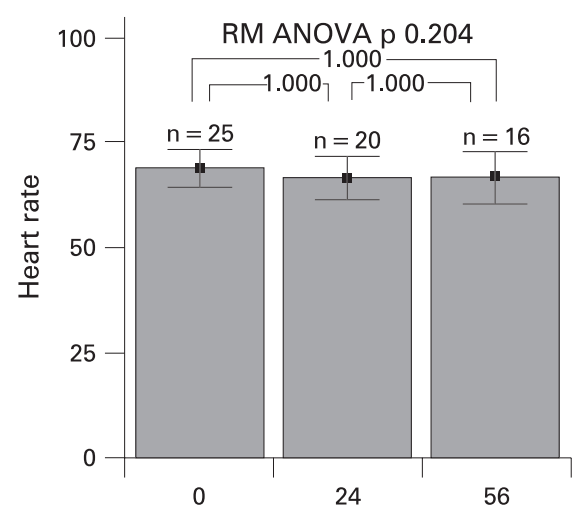

Duration of IFX therapy (weeks)

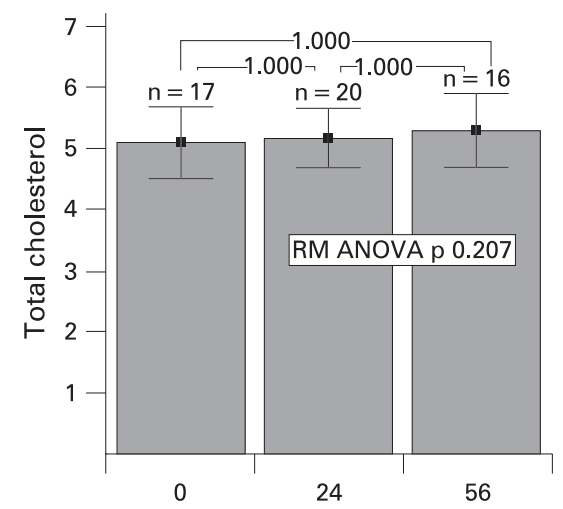

Duration of IFX therapy (weeks)

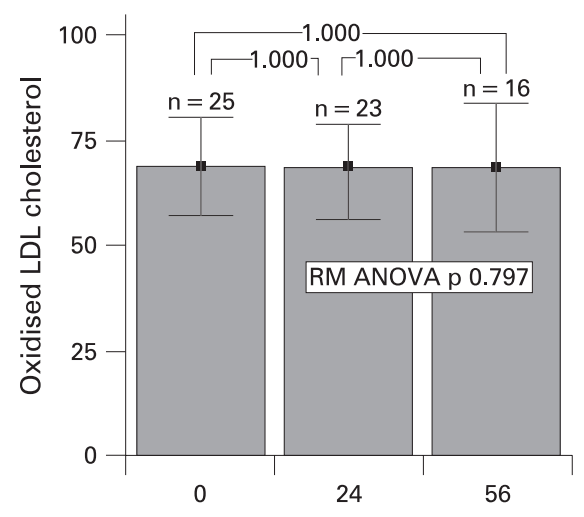

Duration of IFX therapy (weeks)

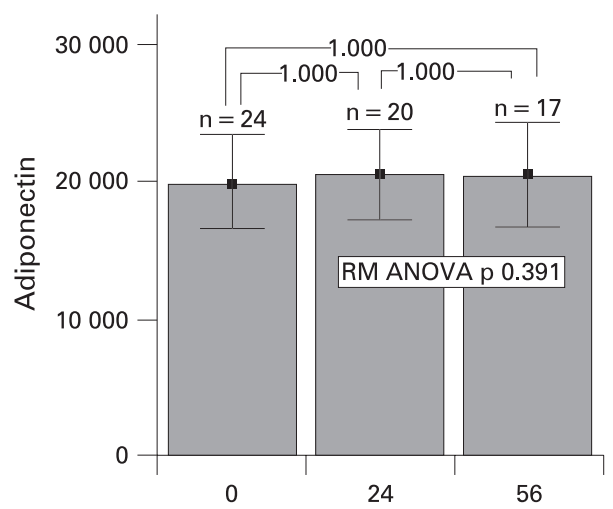

Duration of IFX therapy (weeks)
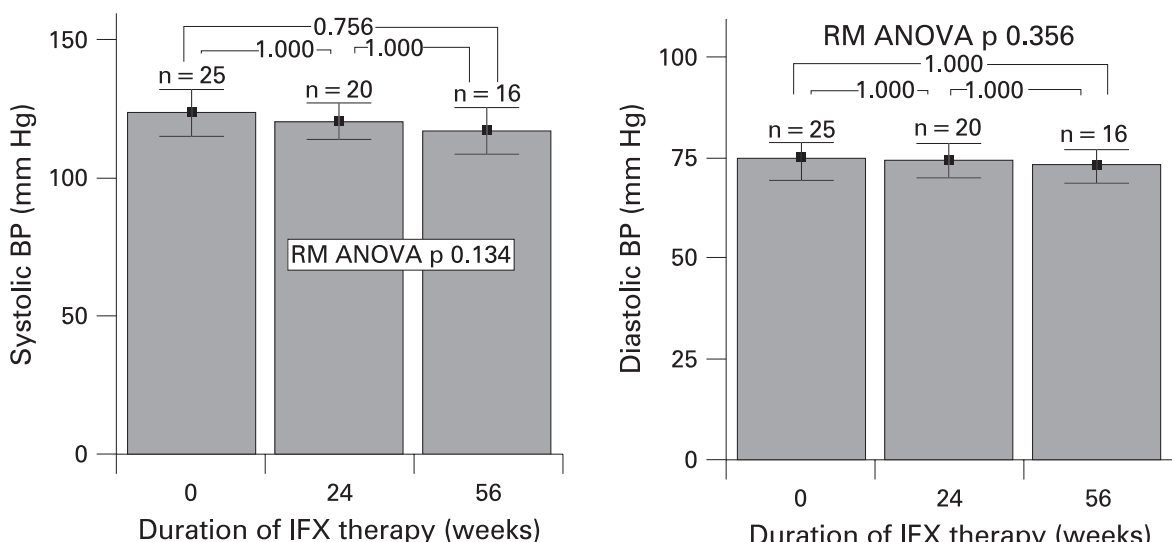

Duration of IFX therapy (weeks)

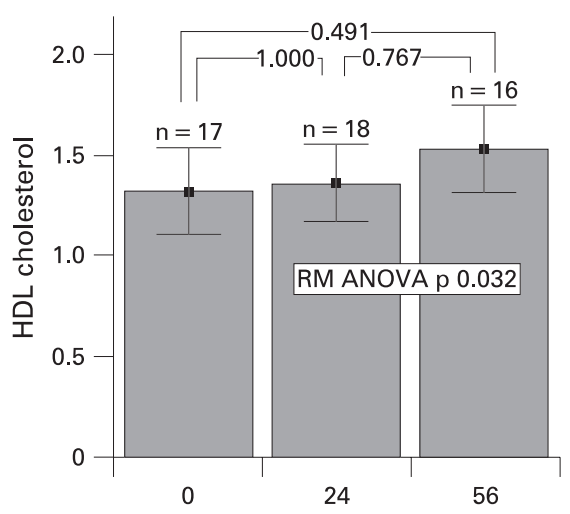

Duration of IFX therapy (weeks)

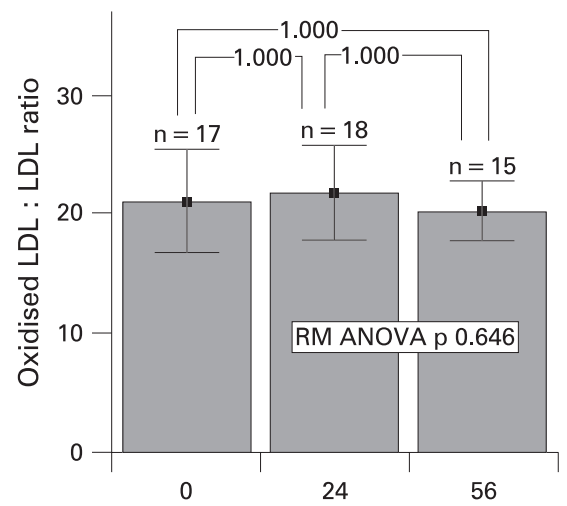

Duration of IFX therapy (weeks)
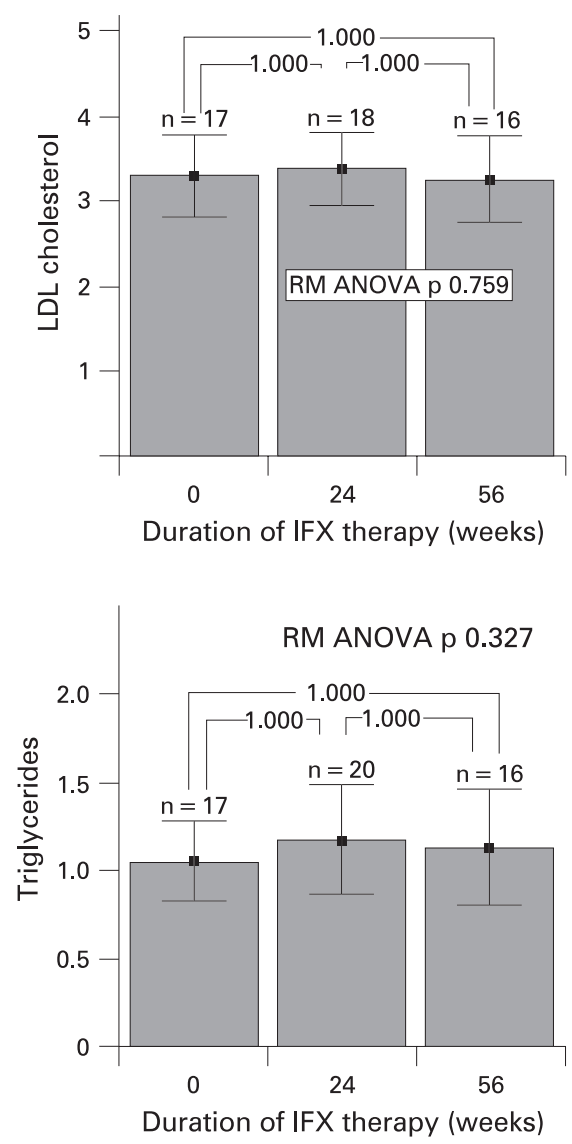

Duration of IFX therapy (weeks)

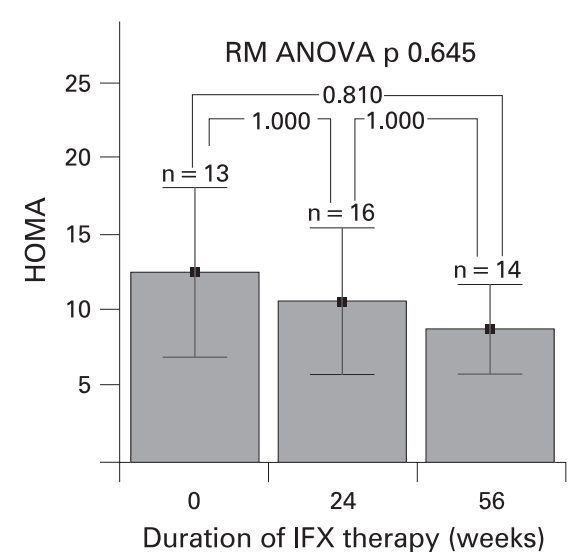

Figure 3 Post hoc analysis: trends in cardiovascular risk factors during treatment with infliximab (IFX). Repeated measures (RM) ANOVA p values indicate the significance of the overall trend while comparisons between paired time points are made by $t$ test adjusted for multiple comparisons (Bonferroni correction). BP, blood pressure; HDL, high-density lipoprotein; HOMA, insulin resistance measured by log homeostasis model assessment; LDL, low-density lipoprotein. 
Table 2 Multivariate analysis for influences on PWV (linear variance, random effects, GLS, accounting for clustering within individuals)

\begin{tabular}{|c|c|c|c|c|}
\hline & \multicolumn{3}{|c|}{ Coefficient } & \multirow[b]{2}{*}{ p Value $(95 \%$ Cl) } \\
\hline & Estimate & Standard error & $\mathbf{z}$ & \\
\hline Duration of infliximab & -0.03 & 0.01 & -3.51 & $<0.001(-0.05$ to -0.01$)$ \\
\hline DAS28 & -0.02 & 0.14 & -0.13 & $0.897(-0.30$ to 0.26$)$ \\
\hline Heart rate & 0.06 & 0.02 & 2.92 & $0.003(0.02$ to 0.10$)$ \\
\hline Systolic BP & 0.02 & 0.01 & 1.30 & $0.195(-0.01$ to 0.04$)$ \\
\hline Triglycerides & 0.48 & 0.40 & 1.22 & $0.221(-0.29$ to 1.27$)$ \\
\hline Constant & 2.42 & 2.24 & 1.08 & $0.282(-1.98$ to 6.81$)$ \\
\hline$\sigma \mathrm{u}$ & 1.26 & & & \\
\hline$\sigma e$ & 0.99 & & & \\
\hline Rho & 0.62 & & & \\
\hline
\end{tabular}

Number of observations $=59$, number of groups $=26, \mathrm{R}^{2}$ overall 0.4129 .

$\mathrm{BP}$, blood pressure; DAS, disease activity score.

that changes in PWV cannot be explained entirely by changes in conventional risk factors.

This is the first study to demonstrate long-term improvement in RA vascular stiffness with TNF $\alpha$-blocking therapy. One small study showed improvement in PWV with etanercept ${ }^{24}$ while others found no change in AI after TNF $\alpha$-blocking therapy, ${ }^{24} 33$ supporting our own work. AI measures vascular stiffness and peripheral resistance, ${ }^{34}$ while PWV purely reflects vascular stiffness ${ }^{20}$ and probably reflects the severity of atherosclerosis and vessel wall calcification. PWV is increased in hypertension, ${ }^{20}$ hypercholesterolaemia, ${ }^{35}$ vasculitis ${ }^{36}$ and $\mathrm{RA}^{24}$ and strongly predicts cardiovascular events in hypertension ${ }^{19}$ and cardiovascular and all-cause mortality in diabetes ${ }^{37}$ and hypertension. ${ }^{38}$

The long-term improvements in vascular stiffness shown in our study support the registry studies demonstrating improvements in vascular disease in patients receiving TNF $\alpha$-blocking drugs. ${ }^{12-14}$ Cohort studies show reductions of cardiovascular events in patients treated with TNF $\alpha$-blocking therapy. ${ }^{13}$ The CORRONA Registry found a reduction of cardiovascular events in patients receiving $\mathrm{TNF} \alpha$-blocking therapy ${ }^{14}$ that was not evident before 6 months of treatment, with greatest benefit after 12 months of treatment. This time course is consistent with our findings using PWV.

Not all studies support the above findings. The British Society for Rheumatology Biologics Register (BSRBR) demonstrated an improvement in the incidence of myocardial infarction in patients with RA responding to TNF $\alpha$-blocking therapy within the first 6 months compared with patients receiving traditional disease-modifying antirheumatic drugs. ${ }^{15}$ Two large nested casecontrol studies have not found a significant improvement in the rates of myocardial infarction ${ }^{39}{ }^{40}$ or stroke ${ }^{39}$ in patients treated with TNF $\alpha$-blocking therapy compared with patients not receiving this therapy. However, these observational studies may be falsely negative due to confounding by indication.

Data regarding the effect of anti-TNF therapy on CIMT is conflicting. CIMT has been shown to be increased in some studies of patients with RA compared with age-matched control subjects. $^{41-43}$ CIMT improves slowly with lipid-lowering therapy. Del Porto et al found significant improvements in CIMT after 12 months of TNF $\alpha$-blocking therapy, ${ }^{21}$ but GonzalezJuanatey showed worsening of CIMT during 2-3 years of TNF $\alpha$-blocking therapy. ${ }^{25}$ Our study may have been underpowered to demonstrate improvements in CIMT, but it is equally possible that anti-TNF therapy prevented increases in CIMT that would have occurred without treatment. We also did not evaluate plaque characteristics (softness, hardness) which may have changed more rapidly.
Methotrexate has been shown to improve mortality in RA. ${ }^{44}$ All patients in the present study were taking stable background methotrexate, so any benefit on cardiovascular function seen in this study will be due to infliximab. However, we were unable to demonstrate synergy of methotrexate and infliximab in relation to vascular structure as has been shown for joint disease activity. ${ }^{8-11}$

The major limitation of our study mainly is the study size. Also, the lack of vascular outcome measures before 24 weeks means that we may have missed any earlier changes to vascular structure and stiffness, particularly if changes did in fact occur earlier but then reverted back to baseline within the time-frame of assessment. This study has, however, shown for the first time that BP measures are stable over a 16-week period and do not exhibit a placebo response. This finding is particularly important since PWV is affected by BP. As BP remains constant, the changes demonstrated for PWV more likely reflect true changes in aortic stiffness.

We examined many potential mechanisms for the long-term improvements in vascular stiffness, including novel modifiable cardiovascular risk factors such as HOMA and adiponectin. Adiponectin is lower in patients at increased risk of cardiovascular disease. ${ }^{27}$ Most of the modifiable cardiovascular risk factors we measured did not correlate with vascular measures at baseline. More importantly, we found no significant changes in these measures over time despite significant improvements in disease activity and vascular stiffness, suggesting that this might have occurred at least partly independent of conventional cardiovascular risk factors. The evidence for a role for conventional risk factors in anti-TNF $\alpha$-mediated cardiovascular protection is conflicting, with some work supporting ${ }^{45}$ and other work not supporting ${ }^{46}$ a role for these factors. It has also been suggested that a reduction in oxidative stress changes the function of lipid particles, ${ }^{47}$ but we found no changes in oxidised LDL levels or the ratio of oxidised LDLto LDL. We are therefore left with the enigma that vascular abnormalities are somehow linked to chronic active RA, but the mechanisms of this link are unclear.

In conclusion, we report that arterial stiffness improves with long-term infliximab treatment in RA and that this seems to occur independently of conventional cardiovascular risk factors. These findings suggest that the combination of TNF $\alpha$-blocking therapy with methotrexate not only reduces joint damage but also vascular "damage" in patients with RA. This is consistent with recent findings of reduced mortality and cardiovascular events after several months in patients with RA receiving TNF $\alpha$-blocking therapy. 
Acknowledgements: The authors thank Karen McNeill and Janine Kelleher for their help in study coordination and data collection.

Funding: This study was supported by a grant from Centocor Pty Ltd. MW was supported by the Arthritis Foundation of Australia.

Competing interests: BK conducts clinical trials and sits on speaker panels for Abbott, Centocor, Schering-Plough, Bristol-Meyers-Squibb and Amgen. SPO conducts trials for Amgen, Abbott, Centocor and Bristol-Myers-Squibb.

Ethics approval: The study was approved by the Guy's Hospital Research Ethics Committee and patients gave written informed consent.

\section{REFERENCES}

1. Gabriel SE, Crowson CS, Kremers HM, Doran MF, Turesson C, O'Fallon WM, et al. Survival in rheumatoid arthritis: a population-based analysis of trends over 40 years. Arthritis Rheum 2003;48:54-8.

2. Jacobsson LT, Turesson C, Hanson RL, Pillemer S, Sievers ML, Pettitt DJ, et al. Joint swelling as a predictor of death from cardiovascular disease in a population study of Pima Indians. Arthritis Rheum 2001:44:1170-6.

3. Wallberg-Jonsson $\mathbf{S}$, Johansson $\mathrm{H}$, Ohman ML, Rantapaa-Dahlqvist S. Extent of inflammation predicts cardiovascular disease and overall mortality in seropositive rheumatoid arthritis. A retrospective cohort study from disease onset. J Rheumatol 1999;26:2562-71.

4. Del Rincon I, Williams K, Stern MP, Freeman GL, Escalante A. High incidence of cardiovascular events in a rheumatoid arthritis cohort not explained by traditional cardiac risk factors. Arthritis Rheum 2001:44:2737-45.

5. Van Doornum S, McColl G, Wicks IP. Accelerated atherosclerosis: an extraarticular feature of rheumatoid arthritis? Arthritis Rheum 2002;46:862-73.

6. Pasceri V, Yeh ET. A tale of two diseases: atherosclerosis and rheumatoid arthritis. Circulation 1999;100:2124-6.

7. Dixon WG, Symmons DP. What effects might anti-TNFalpha treatment be expected to have on cardiovascular morbidity and mortality in rheumatoid arthritis? A review of the role of TNFalpha in cardiovascular pathophysiology. Ann Rheum Dis 2007;66:1132-6.

8. Breedveld FC, Weisman MH, Kavanaugh AF, Cohen SB, Pavelka K, van Vollenhoven $\mathrm{R}$, et al. The PREMIER study: a multicenter, randomized, double-blind clinical trial of combination therapy with adalimumab plus methotrexate versus methotrexate alone or adalimumab alone in patients with early, aggressive rheumatoid arthritis who had not had previous methotrexate treatment. Arthritis Rheum 2006;54:26-37.

9. Smolen JS, Van Der Heijde DM, St Clair EW, Emery P, Bathon JM, Keystone E, et al. Predictors of joint damage in patients with early rheumatoid arthritis treated with high-dose methotrexate with or without concomitant infliximab: results from the ASPIRE trial. Arthritis Rheum 2006:54:702-10.

10. van der Heijde D, Klareskog L, Rodriguez-Valverde V, Codreanu C, Bolosiu H, MeloGomes J, et al. Comparison of etanercept and methotrexate, alone and combined, in the treatment of rheumatoid arthritis: two-year clinical and radiographic results from the TEMPO study, a double-blind, randomized trial. Arthritis Rheum 2006;54:1063-74.

11. Smolen JS, Han C, Bala M, Maini RN, Kalden JR, van der Heijde D, et al. Evidence of radiographic benefit of treatment with infliximab plus methotrexate in rheumatoid arthritis patients who had no clinical improvement: a detailed subanalysis of data from the anti-tumor necrosis factor trial in rheumatoid arthritis with concomitant therapy study. Arthritis Rheum 2005;52:1020-30.

12. Jacobsson LT, Turesson C, Nilsson JA, Petersson IF, Lindqvist E, Saxne T, et al. Treatment with TNF blockers and mortality risk in patients with rheumatoid arthritis. Ann Rheum Dis 2007;66:670-5.

13. Jacobsson LT, Turesson C, Gulfe A, Kapetanovic MC, Petersson IF, Saxne T, et al. Treatment with tumor necrosis factor blockers is associated with a lower incidence of first cardiovascular events in patients with rheumatoid arthritis. J Rheumatol 2005;32:1213-8.

14. Greenberg J, Lin S, Decktor D, Dabbous O, Baumgartner S, Montomery M, et al. Association of duration of TNF antagonist treatment with reduction in cardiovascular outcomes in RA patients (abstract). Arthritis Rheum 2006;54(9 Suppl):422.

15. Dixon WG, Watson KD, Lunt M, Hyrich KL, Silman AJ, Symmons DP. Reduction in the incidence of myocardial infarction in patients with rheumatoid arthritis who respond to anti-tumor necrosis factor alpha therapy: results from the British Society for Rheumatology Biologics Register. Arthritis Rheum 2007:56:2905-12.

16. Kobayashi K, Akishita M, Yu W, Hashimoto M, Ohni M, Toba K. Interrelationship between non-invasive measurements of atherosclerosis: flow-mediated dilation of brachial artery, carotid intima-media thickness and pulse wave velocity. Atherosclerosis 2004;173:13-8.

17. Lehmann ED. Clinical value of aortic pulse-wave velocity measurement. Lancet 1999:354:528-9

18. O'Leary DH, Polak JF, Kronmal RA, Manolio TA, Burke GL, Wolfson SKJ. Carotidartery intima and media thickness as a risk factor for myocardial infarction and stroke in older adults. Cardiovascular Health Study Collaborative Research Group. N Engl J Med 1999;340:14-22.

19. Boutouyrie P, Tropeano Al, Asmar R, Gautier I, Benetos A, Lacolley P, et al. Aortic stiffness is an independent predictor of primary coronary events in hypertensive patients: a longitudinal study. Hypertension 2002;39:10-5

20. Mitchell GF, Dunlap ME, Warnica W, Ducharme A, Arnold JM, Tardif JC, et al. Longterm trandolapril treatment is associated with reduced aortic stiffness: the prevention of events with angiotensin-converting enzyme inhibition hemodynamic substudy. Hypertension 2007;49:1271-7.
21. Del Porto F, Lagana B, Lai S, Nofroni I, Tinti F, Vitale M, et al. Response to antitumour necrosis factor alpha blockade is associated with reduction of carotid intimamedia thickness in patients with active rheumatoid arthritis. Rheumatology (Oxford) 2007:46:1111-5.

22. Vaudo G, Marchesi S, Gerli R, Allegrucci R, Giordano A, Siepi D, et al. Endothelial dysfunction in young patients with rheumatoid arthritis and low disease activity. Ann Rheum Dis 2004;63:31-5.

23. Wong M, Toh L, Wilson A, Rowley K, Karschimkus C, Prior D, et al. Reduced arterial elasticity in rheumatoid arthritis and the relationship to vascular disease risk factors and inflammation. Arthritis Rheum 2003:48:81-9.

24. Maki-Petaja KM, Hall FC, Booth AD, Wallace SM, Yasmin, Bearcroft PW, et al. Rheumatoid arthritis is associated with increased aortic pulse-wave velocity, which is reduced by anti-tumor necrosis factor-alpha therapy. Circulation 2006;114:1185-92.

25. Gonzalez-Juanatey C, Llorca J, Garcia-Porrua C, Martin J, Gonzalez-Gay MA. Effect of anti-tumor necrosis factor alpha therapy on the progression of subclinical atherosclerosis in severe rheumatoid arthritis. Arthritis Rheum 2006:55:150-3

26. Anselmi M, Garbin U, Agostoni P, Fusaro M, Pasini AF, Nava C, et al. Plasma levels of oxidized-low-density lipoproteins are higher in patients with unstable angina and correlated with angiographic coronary complex plaques. Atherosclerosis 2006;185:114-20.

27. Im JA, Kim SH, Lee JW, Shim JY, Lee HR, Lee DC. Association between hypoadiponectinemia and cardiovascular risk factors in nonobese healthy adults. Metabolism 2006;55:1546-50.

28. Arnett FC, Edworthy SM, Bloch DA, McShane DJ, Fries JF, Cooper NS, et al. The American Rheumatism Association 1987 revised criteria for the classification of rheumatoid arthritis. Arthritis Rheum 1988:31:315-24.

29. Ramey DR, Raynauld JP, Fries JF. The health assessment questionnaire 1992: status and review. Arthritis Care Res 1992;5:119-29.

30. Prevoo ML, van't Hof MA, Kuper HH, van Leeuwen MA, van de Putte LB, van Riel PL. Modified disease activity scores that include twenty-eight-joint counts. Development and validation in a prospective longitudinal study of patients with rheumatoid arthritis. Arthritis Rheum 1995:38:44-8.

31. Rabasa-Lhoret R, Bastard JP, Jan V, Ducluzeau PH, Andreelli F, Guebre F, et al. Modified quantitative insulin sensitivity check index is better correlated to hyperinsulinemic glucose clamp than other fasting-based index of insulin sensitivity in different insulin-resistant states. J Clin Endocrinol Metab 2003;88:4917-23.

32. Lassere M, Boers M, van der Heijde D, Boonen A, Edmonds J, Saudan A, et al. Smallest detectable difference in radiological progression. J Rheumatol 1999;26:731-9.

33. Van Doornum S, McColl G, Wicks IP. Tumour necrosis factor antagonists improve disease activity but not arterial stiffness in rheumatoid arthritis. Rheumatology (Oxford) 2005;44:1428-32

34. Sakurai M, Yamakado T, Kurachi H, Kato T, Kuroda K, Ishisu R, et al. The relationship between aortic augmentation index and pulse wave velocity: an invasive study. J Hypertens 2007;25:391-7.

35. Lehmann ED, Watts GF, Gosling RG. Aortic distensibility and hypercholesterolaemia Lancet 1992;340:1171-2.

36. Booth AD, Wallace S, McEniery CM, Yasmin, Brown J, Jayne DR, et al. Inflammation and arterial stiffness in systemic vasculitis: a model of vascular inflammation. Arthritis Rheum 2004;50:581-8.

37. Cruickshank K, Riste L, Anderson SG, Wright JS, Dunn G, Gosling RG. Aortic pulsewave velocity and its relationship to mortality in diabetes and glucose intolerance: an integrated index of vascular function? Circulation 2002;106:2085-90.

38. Laurent S, Boutouyrie P, Asmar R, Gautier I, Laloux B, Guize L, et al. Aortic stiffness is an independent predictor of all-cause and cardiovascular mortality in hypertensive patients. Hypertension 2001;37:1236-41.

39. Solomon DH, Avorn J, Katz JN, Weinblatt ME, Setoguchi S, Levin R, et al. Immunosuppressive medications and hospitalization for cardiovascular events in patients with rheumatoid arthritis. Arthritis Rheum 2006;54:3790-8.

40. Suissa S, Bernatsky S, Hudson M. Antirheumatic drug use and the risk of acute myocardial infarction. Arthritis Rheum 2006;55:531-6.

41. Kumeda Y, Inaba M, Goto $H$, Nagata M, Henmi Y, Furumitsu $Y$, et al. Increased thickness of the arterial intima-media detected by ultrasonography in patients with rheumatoid arthritis. Arthritis Rheum 2002;46:1489-97.

42. Park YB, Ahn CW, Choi HK, Lee SH, In BH, Lee HC, et al. Atherosclerosis in rheumatoid arthritis: morphologic evidence obtained by carotid ultrasound. Arthritis Rheum 2002; 46:1714-9.

43. Del Rincon I, Williams K, Stern MP, Freeman GL, O'Leary DH, Escalante A. Association between carotid atherosclerosis and markers of inflammation in rheumatoid arthritis patients and healthy subjects. Arthritis Rheum 2003:48:1833-40.

44. Krause D, Schleusser B, Herborn G, Rau R. Response to methotrexate treatment is associated with reduced mortality in patients with severe rheumatoid arthritis. Arthritis Rheum 2000:43:14-21.

45. Popa C, van den Hoogen FH, Radstake TR, Netea MG, Eijsbouts AE, den Heijer M, et al. Modulation of lipoprotein plasma concentrations during long-term anti-TNF therapy in patients with active rheumatoid arthritis. Ann Rheum Dis 2007:66:1503-15.

46. Nurmohamed MT. Atherogenic lipid profiles and its management in patients with rheumatoid arthritis. Vasc Health Risk Manag 2007:3:845-52.

47. Chenevard R, Hurlimann D, Bechir M, Enseleit F, Spieker L, Hermann M, et al. Selective COX-2 inhibition improves endothelial function in coronary artery disease. Circulation 2003:107:405-9. 